\title{
Palm tocotrienols decrease levels of pro-angiogenic markers in human umbilical vein endothelial cells (HUVEC) and murine mammary cancer cells
}

\author{
Kanga Rani Selvaduray • Ammu K. Radhakrishnan • \\ Methil Kannan Kutty • Kalanithi Nesaretnam
}

Received: 22 March 2011 / Accepted: 5 April 2011/Published online: 28 April 2011

(C) Springer-Verlag 2011

\begin{abstract}
Anti-angiogenic therapy is widely being used to halt tumour angiogenesis. In this study, the antiangiogenic activity of palm tocotrienol-rich fraction (TRF) and its individual components $(\gamma$ - and $\delta$-tocotrienol) were first investigated in vitro in human umbilical vein endothelial cells (HUVEC) and 4T1 mouse mammary cancer cells. Results showed reduced levels of Interkeukin (IL)-8 and IL-6, two pro-angiogenic cytokines in HUVEC treated with palm tocotrienols compared with $\alpha$-tocopherol $(\alpha-\mathrm{T})$ and control cells $(P<0.05)$. The production of IL-8 and IL-6 was lowest in $\delta$-tocotrienol ( $\delta$-T3)-treated cells followed by $\gamma$-tocotrienol $(\gamma$-T3) and TRF. There was significant $(P<0.05)$ reduction in IL-8 and vascular endothelial growth factor (VEGF) production in 4T1 cells treated with TRF or $\delta$-T3. There was decreased expression of VEGF and its receptors; VEGF-R1 (fms-like tyrosine kinase, Flt-1) and VEGF-R2 (Kinase-insert-domain-containing receptor, KDR/Flk-2) in tumour tissues excised from mice supplemented with TRF were observed. There was also decreased expression of VEGF-R2 in lung tissues of mice
\end{abstract}

This paper is part of a Special Issue entitled "Tocotrienols in health and disease" (Guest editors: Bharat B. Aggarwal and Kalaniti Nesaretnam).

K. R. Selvaduray $(\bowtie) \cdot$ K. Nesaretnam

Malaysian Palm Oil Board, No. 6, Persiaran Institusi,

Bandar Baru Bangi, 43000 Kajang, Selangor, Malaysia

e-mail: krani@mpob.gov.my

K. R. Selvaduray · A. K. Radhakrishnan

Pathology Division, Faculty of Medicine and Health, International Medical University, Kuala Lumpur, Malaysia

M. K. Kutty

Faculty of Medicine and Health Sciences, Malaysian Islamic

Science University, Kuala Lumpur, Malaysia supplemented with TRF. These observations correlate with the smaller tumour size recorded in the tocotrienol-treated mice. This study confirms previous observations that palm tocotrienols exhibit anti-angiogenic properties that may inhibit tumour progression.

Keywords Angiogenesis · Palm tocotrienol · IL-6 · IL-8 · VEGF · VEGF receptors

\section{Introduction}

Angiogenesis is the growth of new blood vessels and is an important natural process occurring in the body. This process is controlled in the healthy body by the presence of angiogenesis activators and inhibitors (Liotta et al. 1991). A perfect balance of angiogenesis modulators is maintained in the normal physiological state. Some of the known angiogenic activators or growth factors include angiogenin, fibroblast growth factors (FGF), interleukin-8 (IL-8), tumour necrosis factor-alpha (TNF- $\alpha$ ), vascular endothelial growth factor (VEGF) and angiopoietin-1. Inhibitors of angiogenesis include angioarrestin, angiostatin, interleukin-12, interferon-alpha/beta/gamma and retinoids (Folkman and Klagsbrun 1987).

Excessive angiogenesis occurs in diseases such as cancer by providing essential growth nutrient via newly formed blood vessel (Hanathan and Folkman 1996) in addition to allowing tumour cells to escape into the circulation (Skobe et al. 1997) and to other organs, thus causing metastasis (Folkman 1990).

Anti-angiogenic therapy is widely being used to halt tumour angiogenesis. Some of the drugs used include Avastin, an anti-VEGF monoclonal antibody (Ferrara 2004), iressa or ZD 1839 (Hirata et al. 2004), thalidomide 
(Zhang et al. 2005) and angiostatin (Cirone et al. 2004). Angiogenesis has also been reported to be stimulated by oxidative stress (Shono et al. 1996; Monte et al. 1997); therefore, anti-oxidants may also exert anti-angiogenic activities.

Palm tocotrienols referred to as the tocotrienol-rich fraction (TRF) consist mainly of a mixture of $\alpha-\gamma$ - and $\delta$-T3 and some $\alpha$-tocopherol $(\alpha$-T). Previous studies have suggested that tocotrienols possess anti-tumour properties (Nesaretnam et al. 1998, 2000; Guthrie et al. 1997). Studies have also shown that one of the anti-tumour mechanisms by tocotrienol is through its anti-angiogenic properties (Nesaretnam et al. 2007). Tocotrienols have been reported to show anti-angiogenic activities in both in vitro and in vivo experimental systems (Inokuchi et al. 2003; Miyazawa et al. 2004; Wong et al. 2009), where it was shown that $\delta$-tocotrienol exhibited the highest anti-angiogenic activity.

In this study, the effects of palm tocotrienols and alphatocopherol on the expression of angiogenic activators namely IL-8, IL-6, VEGF and VEGF receptors were investigated in a cell-based system using human umbilical vein endothelial cells (HUVECs), 4T1 mouse mammary cancer cells as well as in a mouse model. The potential anti-angiogenic mechanisms by palm tocotrienols are also discussed.

\section{Materials and methods}

\section{Isolation of TRF}

The TRF, $\alpha$-T and $\delta$-T3 were obtained from the Malaysian Palm Oil Board (MPOB). Extraction of TRF from palm oil was described by Sundram and Gapor (1992). The final purity of the TRF preparation was 95-99\%, with its composition of (w/w) $\alpha-\mathrm{T}, 32 \%$, and tocotrienols $(\alpha, \gamma, \delta)$, $68 \%$.

\section{Reagents and cell lines}

4T1 mouse mammary cancer cells were purchased from American Type Culture Collection (ATCC). These cells were maintained in RPMI-1640 medium (containing L-Glutamine; Gibco/Invitrogen) supplemented with $10 \%$ Fetal Bovine Serum (FBS) (Gibco/Invitrogen), 1\% penicillin-streptomycin (Gibco/Invitrogen) and 1\% Glutamine (Gibco/Invitrogen) at $37^{\circ} \mathrm{C}$ in a humidified atmosphere containing $5 \% \mathrm{CO}_{2}$. The HUVECs were also purchased from ATCC and cultured in medium 199 (Gibco/Invitrogen), supplemented with $20 \% \mathrm{FBS}, 50 \mu \mathrm{g} / \mathrm{ml}$ Endothelial Cell Growth Supplement (ECGS) (BD Sciences), $100 \mu \mathrm{g} / \mathrm{ml}$ Heparin (Sigma) and 1\% penicilin-streptomycin. Confluent $4 \mathrm{~T} 1$ cells (passages 4-8) were used for the experiments.
Multiplex PCR

Multiplex PCR was carried out to detect the presence of multiple angiogenic-related genes in single RNA samples obtained from tumour tissues of BALB/c mice supplemented with TRF and compared against control.

\section{Total RNA isolation}

Total RNA was extracted from tumour tissues from BALB/c mice injected with mouse mammary cancer cells with Trizol (Invitrogen, Carlsbad, CA) according to the manufacturer's instruction. Total RNA was derived from mouse tumours from control mice (sample C) and experimental mice that were supplemented with TRF (sample E). RNA samples were quantified by measuring the absorbance at 260 and $280 \mathrm{~nm}$ (A260 and A280) in a spectrophotometer. To avoid any contamination with genomic DNA, $3 \mu \mathrm{g}$ of total RNA was incubated for $30 \mathrm{~min}$ at $37^{\circ} \mathrm{C}$ in $50 \mu \mathrm{l}$ of reaction mixture containing $40 \mathrm{mM}$ Tris- $\mathrm{HCl}(\mathrm{pH} 7.2)$, $10 \mathrm{mM} \mathrm{NaCl}, 6 \mathrm{mM} \mathrm{MgCl}_{2}, 2 \mathrm{mM}$ dithiothreitol, $0.04 \mathrm{U} / \mu \mathrm{l}$ RQ1 DNase (Promega) and $0.4 \mathrm{U} / \mu \mathrm{l}$ RNase inhibitor.

\section{cDNA synthesis}

For cDNA preparation for multiplex RT-PCR analysis, $500 \mathrm{ng}$ of DNase-treated total RNA was subjected to cDNA synthesis in $20 \mu \mathrm{l}$ of reaction mixture containing RT buffer (Promega), $5.5 \mathrm{mM} \mathrm{MgCl}_{2}, 500 \mu \mathrm{M}$ dNTP, $2.5 \mu \mathrm{M}$ oligo dT, $0.4 \mathrm{U} / \mu \mathrm{l}$ RNase inhibitor and $1.25 \mathrm{U} / \mu$ l reverse transcriptase. The reverse transcription reaction was carried out by incubating the tube at $42^{\circ} \mathrm{C}$ for $90 \mathrm{~min}$ and heating the tube at $94^{\circ} \mathrm{C}$ for $2 \mathrm{~min}$. Chill the tube on ice for $2 \mathrm{~min}$ and spin the tube briefly. Dilute the cDNA at $70^{\circ} \mathrm{C}$ by double-distilled $\mathrm{dH}_{2} \mathrm{O}$.

\section{Primer design}

The PCR primers were designed with the use of Primer premier 3 (Applied Biosystems). The sequence of each gene was obtained from EMBL/GenBank/DDBJ. Each primer was designed to produce approximately $100 \sim 700$-bp amplicon.

\section{PCR protocol}

Multiplex PCR assays were carried out using Perkin Elmer Cetus 9700 (Applied Biosystems) with ethidium bromide gel electrophoresis. Multiplex PCR amplification was performed in $20 \mu \mathrm{l}$ of reaction mixture containing $3 \mu \mathrm{l}$ of cDNA sample, $10 \mu \mathrm{l}$ of Master Mix (See gene) and genespecific primer sets. PCR was carried out starting with a 15 -min hot start at $95^{\circ} \mathrm{C}$ followed by a denaturation step at 
$94^{\circ} \mathrm{C}$ for $30 \mathrm{~s}$, an annealing step at $63^{\circ} \mathrm{C}$ for $1 \mathrm{~min} 30 \mathrm{~s}$ and an extension step at $72^{\circ} \mathrm{C}$ for $1 \mathrm{~min} 30 \mathrm{~s}$ for 40 cycles. Data were analysed using agarose gel electrophoresis systems (Bio-Rad).

Detection of angiogenic markers in HUVECs treated with TRF and its individual fractions

Levels of angiogenic markers in culture supernatant of HUVEC treated with TRF and its individual fractions were determined using Cytometric Bead Array (CBA) Human Angiogenesis Kit (BD Biosciences) in a flow cytometer (FACS Caliber, BD). Culture supernatant samples of HUVEC with various treatments (TRF, $\gamma$-tocotrienol, $\delta$-tocotrienol, $\alpha$-tocopherol and control) were incubated with antibodies angiogenic markers (IL-8, b-FGF, angiogenin, VEGF, TNF) and immune markers (IL-2, IL-4, IL-6, IL-10, TNF, IFN- $\gamma$ ). Samples were incubated for $3 \mathrm{~h}$ in the presence of PE fluorochrome dye. Samples were then washed and re-suspended in wash buffer $(1 \times$ PBS with detergent). Samples were analysed in a flow cytometer using the CBA software, and results obtained were compared with that of standards provided.

RNA isolation and reverse transcription-polymerase chain reaction (RT-PCR) to analyse IL-8 mRNA levels in $4 \mathrm{~T} 1$ cells

Total RNA was extracted from 4T1 mouse mammary cancer cells treated with $8 \mu \mathrm{g} / \mathrm{ml} \mathrm{TRF}, \alpha-\mathrm{T}, \delta$-T3 and untreated cells using the Trizol solution according to the manufacturer's instructions with some minor modification. Cells treated for $72 \mathrm{~h}$ were lysed with $1.0 \mathrm{ml}$ of Trizol reagent (Invitrogen). The RNA isolated was isolated and frozen at $-80^{\circ} \mathrm{C}$. RNA integrity was checked by denaturing gel electrophoresis. Three micrograms of total RNA
Fig. 1 Multiplex PCR-

Expression of Angiogenesis and related genes in mouse tumour samples. Total RNA was isolated from the samples (a). After reverse transcription, a multiplex polymerase chain reaction with primers for the three genes SET was performed. After 40 cycles of amplification, the samples were electrophoresed and stained with ethidium bromide. $P$ Positive size marker, Lane 1: $\mathrm{C}$, Lane 2: E (c, d, e). cDNA Normalization using House Keeping Gene Panels [SDHA succinate dehydrogenase complex, subunit A, HPRT1 hypoxanthine guanine phosphoribosyltransferase 1, $B 2 M$ beta-2-microglobulin] (b)

$\mathbf{a}$

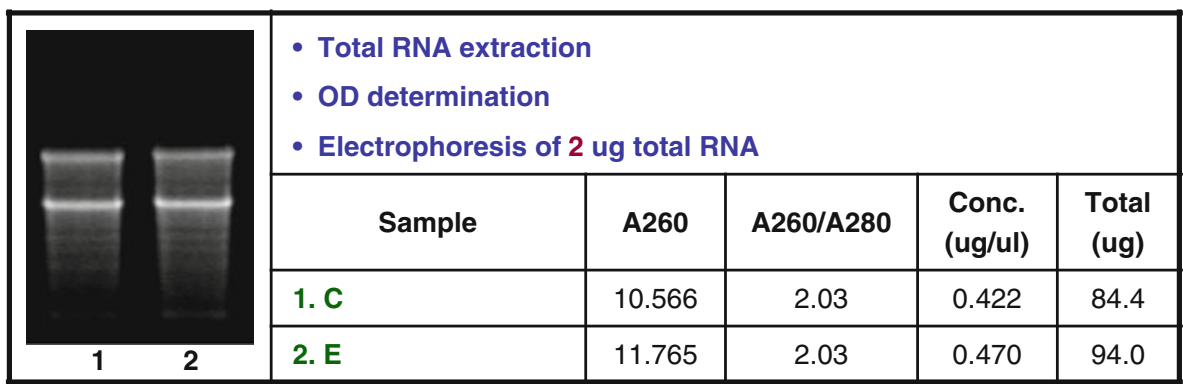

b

HouseKeeping gene SET

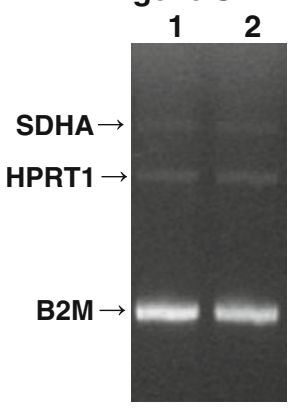

d

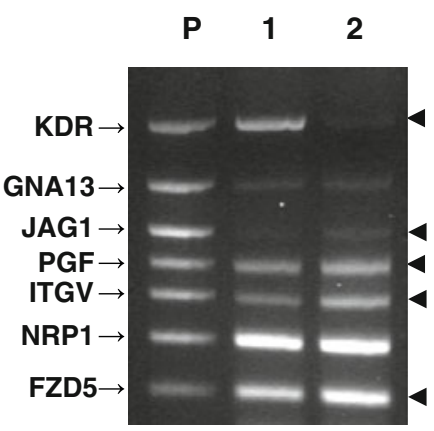

c

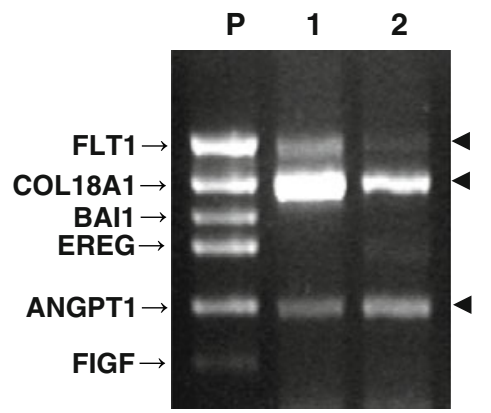

e SET 3

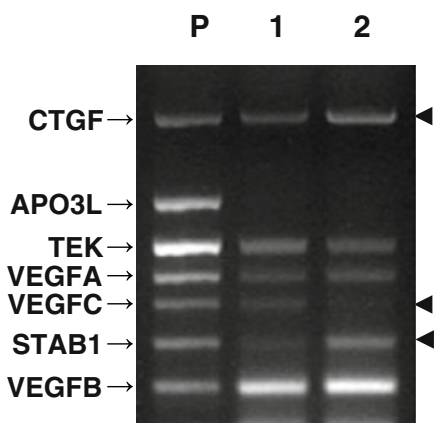


was used for reverse transcription using Superscript II RT (Invitrogen), and $3 \mu \mathrm{l}$ of cDNA was used for polymerase chain reaction (PCR). The primers used were as follows: forward: 5'-CAGGAA TTGAAT GGGTTT GCT-3', reverse: $5^{\prime}$-TCACAA CATCAC TGTGAG GT-3' (115 bp) for IL-8, and forward: $5^{\prime}$-GTGGGG CGCCCC AGGCAC CA- ${ }^{\prime}$, reverse: $5^{\prime}$-CTCCTT AATGTC ACGCAC GATT TC-3' (540 bp) for $\beta$-actin.

\section{QuantiGene assay}

QuantiGene assay was used for direct quantification of VEGF and IL-8 levels in RNA from 4T1 cells treated with TRF, $\delta$-T3, $\alpha$-T and compared against untreated control cells. The assay employs a sandwich nucleic acid hybridization method that uses branch DNA (bDNA) molecules to amplify signal from captured target RNA. The assay was carried out as described in QuantiGene 2.0 Reagent System User Manual (Panomics, Fremont, CA). About 100 ng RNA/well was loaded into 96-well plate for the detection of target probe, and $1 \mathrm{ng}$ RNA/well was loaded for the detection of $\beta$-actin. Working Probe Set was prepared for each target, and capturing of target RNA was carried out at $55^{\circ} \mathrm{C}$ overnight. Following the overnight hybridization, signal amplification and detection steps were carried out using target-specific preamplifiers, amplifiers and label probes. Signal detection was carried out by the addition of chemilumigenic substrate that generates a luminescent signal that is proportionate to the amount of target mRNA present in the sample.

\section{Immunohistochemistry}

Immunohistochemical staining procedure was used to detect pro-angiogenic marker, VEGF and its receptor, VEGF-R2 in formalin-fixed paraffin-embedded sections of tumour and lung tissues obtained from $\mathrm{BALB} / \mathrm{c}$ mice inoculated with $4 \mathrm{~T} 1$ mouse mammary cancer cells that were supplemented and not supplemented with TRF. Standard staining procedure was performed without antigen retrieval. Firstly, the tissue sections were deparaffinized and then rehydrated. Then, the primary antibodies (VEGF and VEGF-R2, Abcam, USA) were applied at appropriate concentrations for $1 \mathrm{~h}$ at $37^{\circ} \mathrm{C}$. Then, the relevant horse-radish peroxidase (HRP)-conjugated secondary antibodies (Abcam, USA) were then applied, and the staining was visualized after addition of the substrate for HRP and counterstained with Haemotoxylin. Slides were then dehydrated and mounted with DPX.

\section{Statistical analysis}

The data were expressed as mean \pm SD unless otherwise indicated and were tested with 1-way ANOVA, followed by Tukey test. Differences were considered significant at $P<0.05$.

\section{Results}

Multiplex PCR

Multiplex PCR carried out to simultaneously detect multiple angiogenic-related genes in single RNA samples obtained from tumour tissues of BALB/c mice supplemented with TRF and compared against control. Results obtained showed down-regulation in the expression of VEGF-C (an angiogenic promoter), VEGF-R1 (Flt-1) and VEGF-R2 (KDR) which represent receptors for VEGF, in tumour RNA from BALB/c mice supplemented with TRF compared with control (Fig. 1). These results correlated with the observation of a smaller tumour in experimental mice.

Suppression of IL-8 and IL-6 in HUVEC culture by TRF and individual fractions of tocotrienols

Cytometry Bead Array (CBA) detection of angiogenic and Th1/Th2 markers in HUVEC culture treated with $8 \mu \mathrm{g} / \mu \mathrm{l}$ TRF, $\gamma$-T3, $\delta$-T3, $\alpha-\mathrm{T}$ and in untreated control cells showed suppression of IL-8 (Fig. 2a) and IL-6 (Fig. 2b) by TRF and its individual fractions. Expressions of IL- 8 and IL-6 were lowest in HUVEC treated with $\delta$-T3 followed by $\gamma$-T3 and TRF. High expressions were observed in cells treated with $\alpha$-T and in control cells (Fig. 2c).

\section{Suppression of IL-8 and VEGF mRNA levels} in $4 \mathrm{~T} 1$ cells

RT-PCR was carried out to observe the level of angiogenic marker, IL-8 in RNA extracted from 4T1 cells treated with TRF, $\delta$-T3, $\alpha$-T and control cells. Results from RT-PCR showed lowest expression of IL-8 in cells treated with $\delta$-T3 followed by TRF, $\alpha$-T and control cells (Fig. 3).

Quantitative analysis of the levels of two major angiogenic markers, IL-8 and VEGF, was carried out using QuantiGene assay. Expression levels of both IL-8 and VEGF showed >twofold down-regulation in 4T1 cells treated with $\delta$-T3 and TRF. A higher reduction in the expressions of VEGF and IL-8 was observed in 4T1 cells treated with $\delta$-T3 and TRF compared with $\alpha$-T (Fig. 4).

VEGF-R2 expression by Immunohistochemistry

Lung tissue sections of $\mathrm{BALB} / \mathrm{c}$ mice were stained for VEGF-R2 (receptor for VEGF). In this experiment, VEGF-R2 was strongly expressed in invading tumour cells in the 

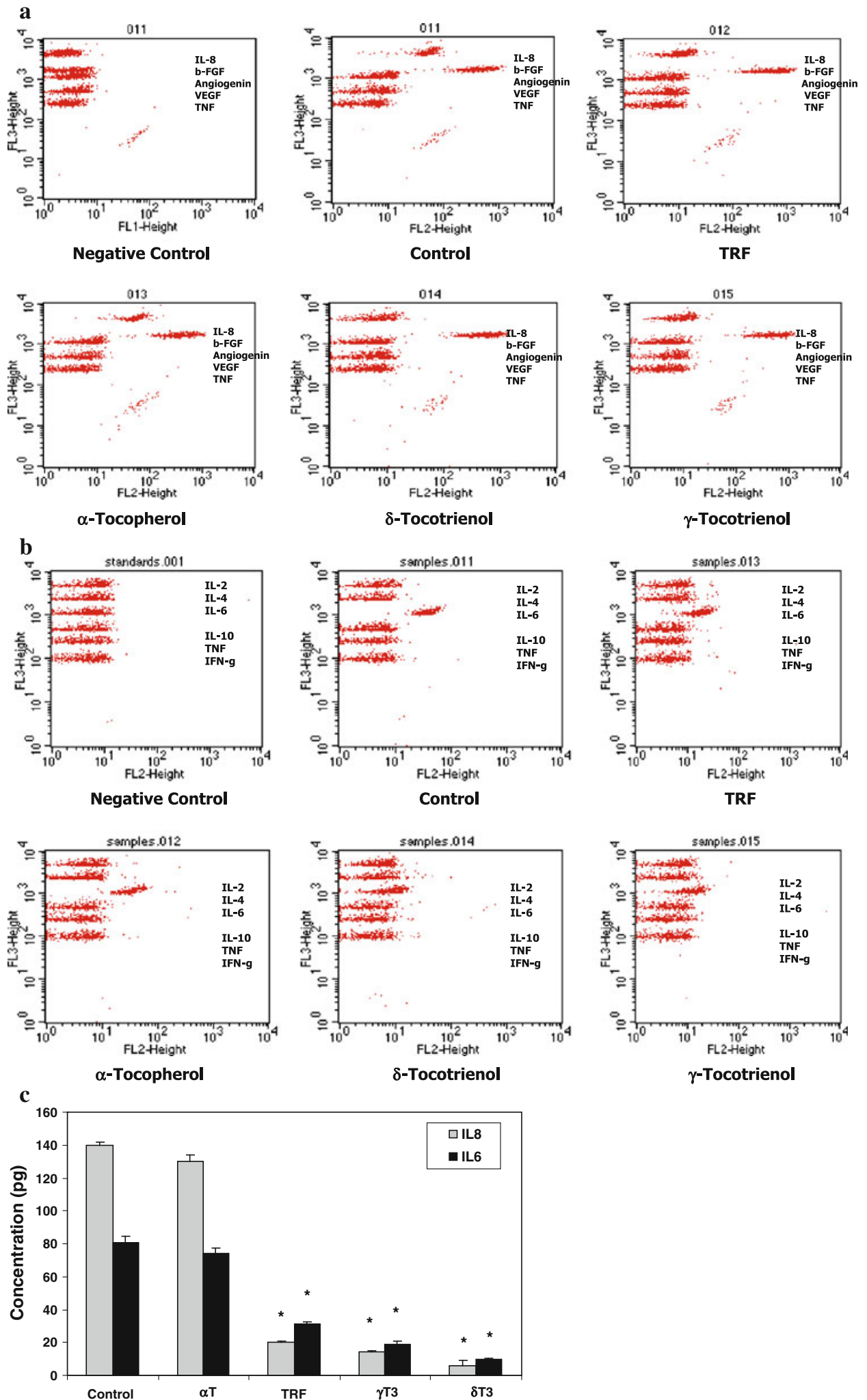

Fig. 2 Flow cytometry analysis using Cytometric Bead Array (CBA). a Dot plot distribution of analytes in HUVEC culture supernatant of various treatments using CBA Human Angiogenesis Kit b Dot plot distribution of analytes in HUVEC culture supernatant of various treatments using CBA Human Th1/Th2 Cytokine Detection Kit $\mathbf{c}$ Concentrations of IL-8 and IL- 6 in HUVEC culture supernatant of various treatments using CBA Kit $(* P<0.05)$ 


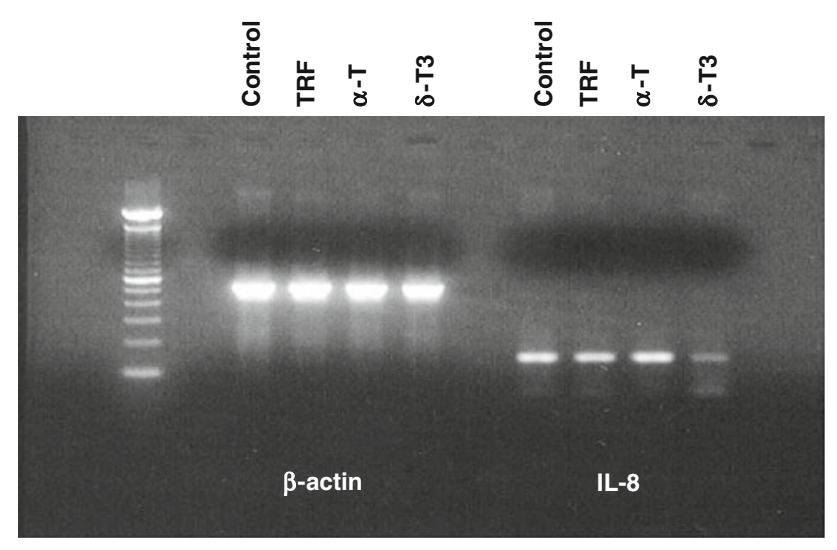

Fig. 3 RT-PCR detection of levels of IL-8 in RNA samples from $4 \mathrm{~T} 1$ cells with various treatments against control

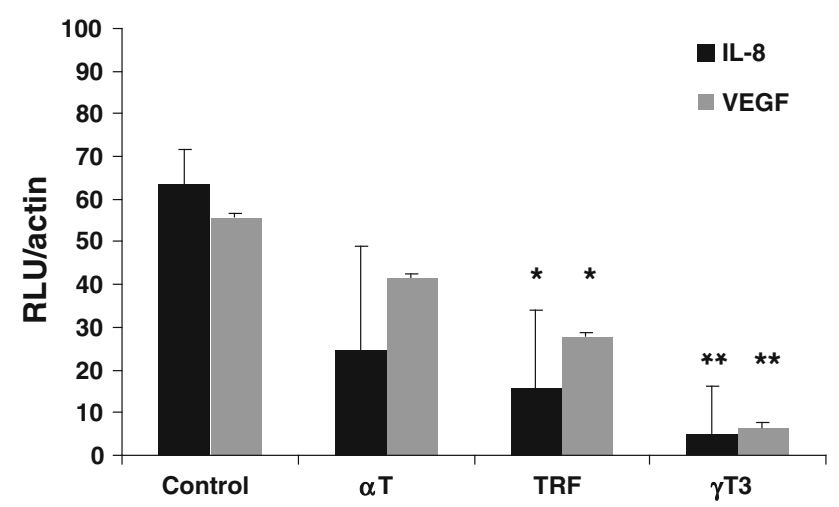

Fig. 4 QuantiGene analysis of IL-8 and VEGF expressions in 4T1 RNA samples with various treatments against control

lungs of control mice not supplemented with TRF (Fig. 5a). In contrast, the expression of VEGF-R2 in tumour cells in the lung tissue of TRF-supplemented mice was comparatively weaker than in control mice (Fig. 5b). In general, there were very few invading tumour cells in the lung tissues of TRF-supplemented mice.

\section{Discussion}

Angiogenesis plays an important role in the progression of cancer and has been the major focus area for developing cancer treatment strategies. In the present study, we investigated the anti-angiogenic activity of TRF in HUVECs and 4T1 mouse mammary cells. Tocotrienols were found to lower the levels of IL- 8 and IL- 6 in HUVEC culture. Levels of VEGF and IL-8 were also reduced in 4T1 cells by TRF and $\delta$-T3. RNA levels of VEGF, VEGF-R1 (Flt-1) and VEGF-R2 (KDR) were significantly reduced in BALB/c mice with TRF treatment. In contrary, $\alpha$-T did not show any inhibition of angiogenesis.
The angiogenesis process involves a number of steps which include endothelial cell proliferation, migration, differentiation and tube formation. Therapeutic intervention of angiogenesis is being focused at these steps to serve as potential targets. Hence, evaluation of anti-angiogenic effects on any of these processes is extremely crucial. Antiangiogenic drugs have been developed to target inhibition of endothelial cell proliferation, interference with endothelial cell adhesion and migration as well as interference with matrix metalloproteinases (MMPs; Griffioen and Molema 2000).

IL-6 and IL-8 have also been shown to promote angiogenesis. IL-6 increases levels of VEGF through stimulation of platelets (Caine et al. 2004), while IL-8 enhances proliferation and survival of endothelial cells and the production of MMPs which are involved in the degradation of basement membrane during blood vessel formation (Li et al. 2003). In this study, in vitro findings of decreased levels of IL-6 and IL-8 in HUVEC and decreased levels of VEGF and IL-8 in 4T1 cells treated with tocotrienols support the anti-angiogenic properties of tocotrienols.

There is increasing evidence, indicating that tocotrienols possess cancer chemopreventive properties (Nesaretnam et al. 2000; Stone et al. 2004). Tocotrienols from palm oil have been shown to inhibit proliferation and growth of various cancer cells including the breast, prostate and colon cancer cells both in vitro and in vivo (Nesaretnam et al. 1992, 1995, 1998, 2004; Guthrie et al. 1997; Agarwal et al. 2004; Srivastava and Gupta 2006; Gould et al. 1991).

In this study, RNA samples were isolated from tumour tissues excised from 4T1 mouse mammary cancer cellinduced $\mathrm{BALB} / \mathrm{c}$ mice that were supplemented with TRF as well as control mice. The expression of VEGF RNA in tumour of mice treated with $1 \mathrm{mg}$ TRF was significantly lower than those without TRF treatment. These results correlated with the observation that TRF-treated mice presented smaller tumour than control mice (data not shown). Decreased expression of the VEGF mRNA in tumour of TRF-treated mice was shown from the multiplex PCR experiment (Fig. 1). Our results therefore clearly showed that tumour size corresponds proportionally with VEGF levels. Similar observation has been reported when serum levels of VEGF were found to be significantly lower in mice treated with TRF (Wong et al. 2009). VEGF plays a crucial role as regulator of tumour angiogenesis (Poon et al. 2001) apart from being one of the most important signals in the multi-step process of tumour angiogenesis. It has been reported to play an important role in regulating major angiogenic processes such as proliferation, migration and differentiation, as well as protection from apoptosis (Wong et al. 2009). Studies have clearly shown that highserum VEGF levels correlated with advanced disease in cancer patients (Salven et al. 1997; Kumar et al. 1998; 


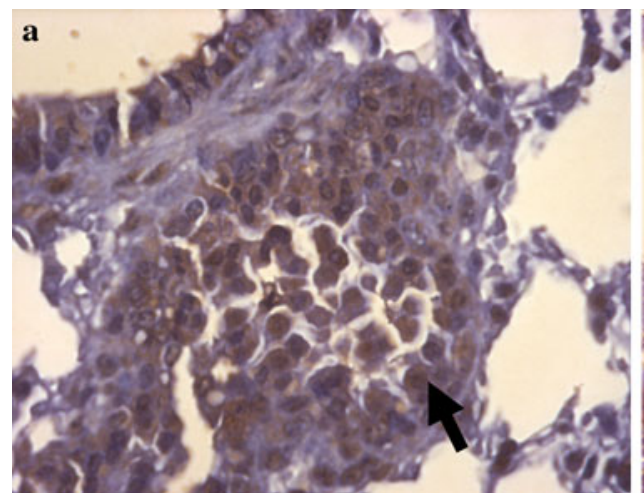

Fig. 5 a Strong expression of VEGF-R2 in tumour cells in lung tissue of a control mouse (magnification $\times 40$; Positive expression of VEGF-R2 appear as brown stains in cells) b Weak expression of

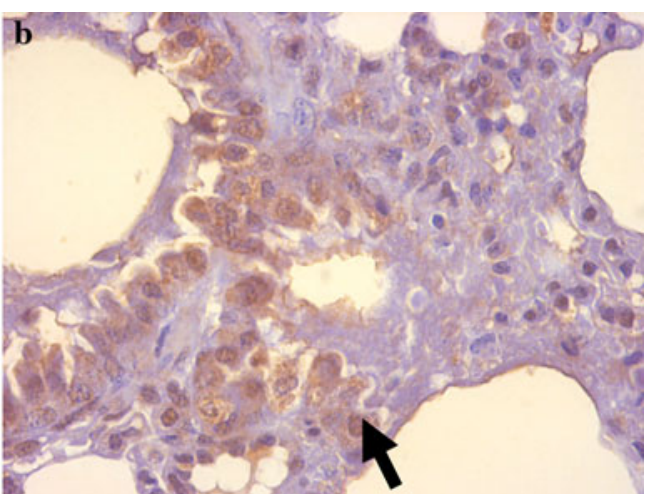

VEGF-R2 in tumour cells in lung tissue of an experimental mouse (magnification $\times 40$; Positive expression of VEGF-R2 appear as brown stains in cells)

Fig. 6 Schematic representation of the possible effects of tocotrienols (T3) in the process of angiogenesis. Tocotrienols do not only reduce expression levels of VEGF but also of its receptors, Flt-1 and KDR, which regulate the proliferation of endothelial cells. Tocotrienols also hinder the expression of IL- 8 which regulates proliferation of endothelial cells and production of matrix metalloproteinases (MMPs) which in turn initiate the degradation of basement membrane surrounding blood vessel in the process of angiogenesis. In addition, tocotrienols reduce the expression of IL-6 which increases levels of VEGF through stimulation of platelets. Our previous study has shown that tocotrienols inhibit migration and proliferation of endothelial cells. Hence, the diagram shows the possible sites where tocotrienols inhibit the angiogenic process
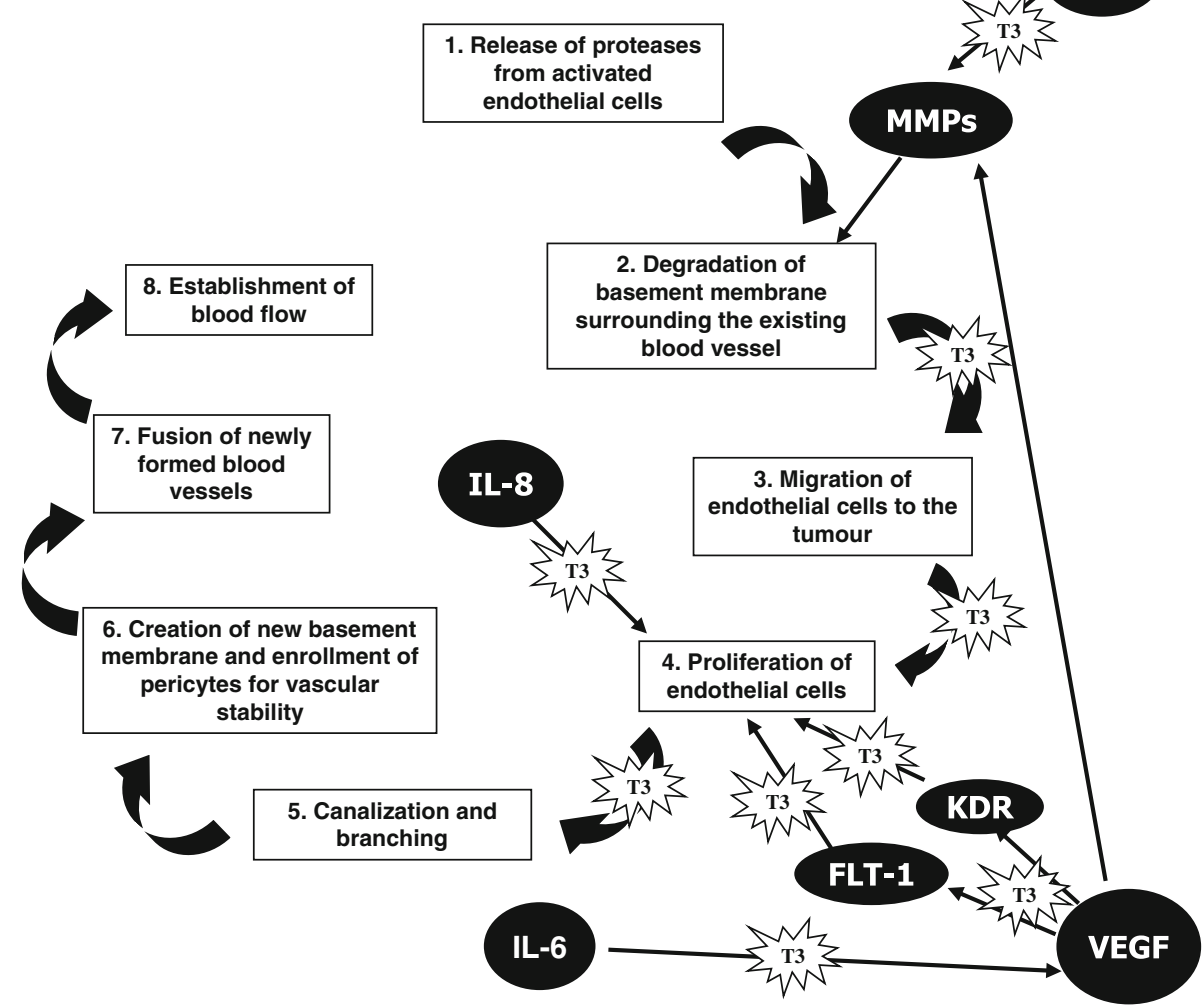

Karayiannakis et al. 2002). Previous studies carried out in our laboratory have shown that 4T1 tumour volume in TRF-treated BALB/c mice significantly reduced compared with those without TRF treatment. Such observation may be partly due to the anti-angiogenic effect of TRF (Nakagawa et al. 2007).

VEGF revealed a high binding affinity to two receptor tyrosine kinases, namely VEGF-R1 (fms-like tyrosine kinase, Flt-1) and VEGF-R2 (Kinase-insert-domaincontaining receptor, KDR/Flk-2; Ferrara 2004). Reduction in VEGF will decrease the binding of VEGF to the VEGF receptors. Our findings using multiplex PCR not only indicated reduced expression of VEGF but also decreased expressions of KDR and Flt-1 in tumour samples from BALB/c mice supplemented with TRF (Fig. 1). In addition, in this study, immunohistochemical detection of VEGF-R2 is also shown to be reduced in lung tissues of mice treated with TRF (Fig. 5a and b).

The binding of VEGF to its receptors is important for the activation of PI3K/PDK/Akt signalling in endothelial 
cells, leading to increased proliferation, survival, permeability and migration of cells (Hoeben et al. 2004). Several studies reported the anti-angiogenic effect of tocotrienols via the suppression of growth factor-dependent activation of PI3K/PDK/Akt signalling in neoplastic mammary cells (Samant and Sylvester 2006) and HUVEC (Nakagawa et al. 2007). Based on our findings, we hypothesize that since VEGF protein is low in the circulatory system, binding of VEGF to VEGF-Rs is reduced. A further suppression is indicated with reduced VEGF-R2 expression. In addition, in the presence of TRF, VEGF levels may also be suppressed with decreasing IL-6 levels while proliferation and migration may be hindered by the decreased levels of IL-8 (Figs. 2, 3 and 4).

In conclusion, this study clearly shows that tocotrienols but not tocopherols possess anti-angiogenic by reducing expression of angiogenic promoters. We therefore confirm previous findings that tocotrienols may act as a potential agent for the prevention of cancer progression through angiogenesis.

A schematic representation of the possible effects of tocotrienols in the process of angiogenesis is shown in Fig. 6.

Acknowledgments We thank the Malaysian Palm Oil Board and the International Medical University (IMU 131-2007) of Kuala Lumpur for funding the study.

\section{References}

Agarwal MK, Agarwal ML, Athar M, Gupta S et al (2004) Tocotrienol-rich fraction of palm oil activates p53, modulates $\mathrm{Bax} / \mathrm{Bcl} 2$ ratio and induces apoptosis independent of cell cycle association. Cell Cycle 3:1-7

Caine GJ, Lip GY, Stonelake PS et al (2004) Platelet activation, coagulation and angiogenesis in breast and prostate carcinoma. Thromb Haemost 92:185-190

Cirone P, Bourgeois JM, Shen F et al (2004) Combined immunotherapy and antiangiogenic therapy of cancer with microencapsulated cells. Hum Gene Ther 15:945-959

Ferrara N (2004) Vascular endothelial growth factor: basic science and clinical progress. Endocr Rev 25:581-611

Folkman J (1990) What is the evidence that tumors are angiogenesis dependent? J Natl Cancer Inst 82:4-6

Folkman J, Klagsbrun M (1987) Angiogenic factors. Science 235:442-447

Gould MN, Haag JD, Kennan WS et al (1991) A comparison of tocopherol and tocotrienol for the chemoprevention of chemically induced rat mammary tumours. Am J Clin Nutr 53:1068S1070S

Griffioen AW, Molema G (2000) Angiogenesis: potentials for pharmacologic intervention in the treatment of cancer, cardiovascular diseases, and chronic inflammation. Pharmacol Rev $52: 237-268$

Guthrie N, Gapor A, Chambers AF et al (1997) Inhibition of proliferation of estrogen receptor-negative MDA-MB-435 and positive MCF-7 human breast cancer cells by palm oil tocotrienol and tamoxifen, alone and in combination. J Nutr 127:544S$548 \mathrm{~S}$
Hanathan D, Folkman J (1996) Patterns and imaging mechanism of the angiogenic switch during tumorigenesis. Cell 186:353-364

Hirata A, Uehara H, Izumi K et al (2004) Direct inhibition of EGF receptor activation in vascular endothelial cells by gefitinib ('Iressa', ZD1839). Cancer Sci 95:614-618

Hoeben A, Landuyt B, Highley MS et al (2004) Vascular endothelial growth factor and angiogenesis. Pharmacol Rev 56:549-580

Inokuchi H, Hirokane H, Tsuzuki T et al (2003) Anti-angiogenic activity of tocotrienol. Biosci Biotechnol Biochem 67:1623-1627

Karayiannakis AJ, Syrigos KN, Polychronidis A et al (2002) Circulating VEGF levels in the serum of gastric cancer patients: correlation with pathological variables, patient survival, and tumor surgery. Ann Surg 236:37-42

Kumar H, Heer K, Lee PW et al (1998) Preoperative serum vascular endothelial growth factor can predict stage in colorectal cancer. Clin Cancer Res 4:1279-1285

Li A, Dubey S, Varney ML et al (2003) IL-8 directly enhanced endothelial cell survival, proliferation, and matrix metalloproteinases production and regulated angiogenesis. J Immunol 170:3369-3376

Liotta LA, Steeg PS, Stetler-Stevenson WG (1991) Cancer metastasis and angiogenesis: an imbalance of positive and negative regulation. Cell 64:327-336

Miyazawa T, Inokuchi $\mathrm{H}$, Tsuzuki $\mathrm{T}$ et al (2004) Anti-angiogenic potential of tocotrienol in vitro. Biochem 69:67-69

Monte M, Davel LE, Sacerdote de Lustig E (1997) Hydrogen peroxide is involved in activation mechanisms to include angiogenesis. Eur J Cancer 33:676-682

Nakagawa K, Shibata A, Yamashita A et al (2007) In vivo angiogenesis is suppressed by unsaturated vitamin $\mathrm{E}$, tocotrienol. J Nutr 137:1938-1943

Nesaretnam K, Khor HT, Ganeson J et al (1992) The effects of vitamin $\mathrm{E}$ tocotreinols from palm oil on chemically induced mammary carcinogenesis in female rats. Nutr Res 12:879-892

Nesaretnam K, Guthrie N, Chambers AF et al (1995) Effect of tocotrienol on the growth of a human breast cancer cell line in culture. Lipids 30:1139-1143

Nesaretnam K, Stephen R, Darbre PD (1998) Tocotrienols inhibit the growth of human breast cancer cells irrespective of estrogen receptor status. Ibid 33:461-469

Nesaretnam K, Dorasamy S, Dabre D (2000) Tocotrienol inhibit growth of ZR-75-1 breast cancer cells. Int J Food Sci Nutr 51:S95-S105

Nesaretnam K, Ambra R, Selvaduray KR et al (2004) Tocotrienolrich fraction from palm oil affects gene expression in tumours resulting from MCF-7 cell inoculation in athymic mice. Lipids 39:459-467

Nesaretnam K, Wong WY, Basri MW (2007) Tocotrienols and cancer: beyond antioxidant activity. Eur J Lipid Sci Technol 109:445-452

Poon RTP, Fan ST, Wong J (2001) Clinical implications of circulating angiogenic factors in cancer patients. J Clin Oncol 19:1207-1225

Salven P, Teerenhovi L, Joensuu H (1997) A high pretreatment serum vascular endothelial growth factor concentration is associated with poor outcome in non-Hodgkin's lymphoma. Blood 90:3167-3172

Samant GV, Sylvester PW (2006) $\gamma$-Tocotrienol inhibits ErbB3dependent PI3K/Akt mitogenic signalling in neoplastic mammary epithelial cells. Cell Prolif 39:563-574

Shono T, Ono M, Izumi $\mathrm{H}$ et al (1996) Involvement of the transcription factor NF-kappaB in tubular morphogenesis of human microvascular endothelial cells by oxidative stress. Mol Cell Biol 16:4231-4239

Skobe M, Rockwell P, Goldstein N et al (1997) Halting angiogenesis suppresses carcinoma cell invasion. Nat Med 3:1222-1227 
Srivastava JK, Gupta S (2006) Tocotrienol-rich fraction of palm oil induces cell cycle arrest and apoptosis selectively in human prostate cancer cells. Biochem Biophy Res Comm 346:447-453

Stone WL, Krishnan K, Campbell SE et al (2004) Tocopherols and the treatment of colon cancer. Ann NY Acad Sci USA 1031:223-233

Sundram K, Gapor A (1992) Vitamin E from palm oil. Its extraction and nutrition properties. In: Peter JB (ed) Lipid Technology. Bridgwater, England, pp 137-141
Wong WY, Selvaduray KR, Cheng HM et al (2009) Suppression of tumor by palm tocotrienols via the attenuation of angiogenesis. Nutr Can 61:367-373

Zhang ZL, Liu ZS, Sun Q (2005) Effects of thalidomide on angiogenesis and tumor growth and metastasis of human hepatocellular carcinoma in nude mice. World J Gastroenterol 11:216-220 